\title{
(QJPS)
}

Vol. 23, No.04, pp. 14-20,Year-2018

\section{Study on the practices nonlinear optics with AGS and ZGP crystals}

\author{
Raad Sh. Alnayli
}

College of Education, University of Al-Qadisiyah, Iraq

Email:, Raad.Alnayli@qu.edu.iq

\section{DOI: $10.29350 /$ jops.2018.23.4.915}

\begin{abstract}
:
In thispaperby means of the new method known as Ž-Scan technique, the nonlinear optical properties for Zink Germanium Di phosphate $\mathrm{ZnGeP}_{2}$ and Sliver Gallium Selenite $\left(\mathrm{AgGase}_{2}\right)$ have been studied . Ž-scan experience was doneby laser called $\mathrm{Nd}$-yag at $532 \mathrm{~nm}$ and $1064 \mathrm{~nm}$ and output of $(80,40,35$ and 25) $\mathrm{mW}$, in two parts. The first one was a closed-aperture placed ahead of the detector to calculate the index of nonlinear refractive. While the second part; the aperture ahead the detector was taken away (open manhole) to calculatethecoefficient of nonlinear absorption. The experiential outcomes exhibit that the Sliver Gallium Selenite $\left(\mathrm{AgGaSe}_{2}\right)$ exhibits positive refractive index (self-focusing) and saturation absorption, while the experimental results for Zink Germanium Di phosphate $\mathrm{ZnGeP}_{2}$ exhibits negative nonlinear refraction(self-defocusing)and two-photon absorption.
\end{abstract}

KEYWORDS:Ž-Scan method, Nd-yag laser, Zink GermaniumDi phosphate, Sliver Gallium Selenite, nonlinear optics, self-focusing. 


\section{(QJPS)}

Vol. 23, No.04, pp.14-20, Year-2018

\section{Introduction}

TheNonlinear optics (NLO) is the studied of all the cases that happen because of the association of intense light with matter(Body, 2007), (Marder, 1991). The interact with a nonlinear optical crystals causes an alteration of the optical properties of the arrangement, and the next photon that arrives sees a different material. Usually only laser light is sufficiently intense to create NLO phenomena; therefore the beginning of this research field is often taken to be the revelationof second-harmonic generation by Franken et al. in 1961(Peter.A. Franken et.al, 1961), the year after the discovering of the first laser by (Maiman, 1960). Despitethe fact that the perception ofmost nonlinearly optical phenomena requires laser radiation, some classes of nonlinear-optical effects were known some time before the innovation of the laser. The most prominent crystals of such phenomena include Pockles and Kerr electro optic effects(Träger, 2012).The theory of nonlinear optics expands on the surely knewtheory of linearity optics, especially that part known as the interaction of light and matter. Ordinary matter consists of a collection of positively charged cores (of atoms or molecules) and surrounding negatively charged electrons light interacts primarily with matter by means ofthe valence electrons in the external shells of electron orbitals. The basic parameter in this light-matter interaction theory is the electronic polarization of the material instigated by light (Sutherland, 2003).

\section{Materials and Methods:}

\subsection{Characteristics of ZinkGermanium phosphateand Sliver Gallium Selenite}

Zink Germanium Di phosphate $\mathrm{ZnGeP}_{2}$ so indicated as ZGP crystal is very suitable for difference frequency conversion owing to its low absorption in infrared (IR) and far infrared (FIR) spectral range (Krishnan and et al, 2002)(Paschotta, 2004), Therefore this type of materials is being on of the most highly efficiency nonlinear optical media for frequency conversion of the middle infrared wavelengths.

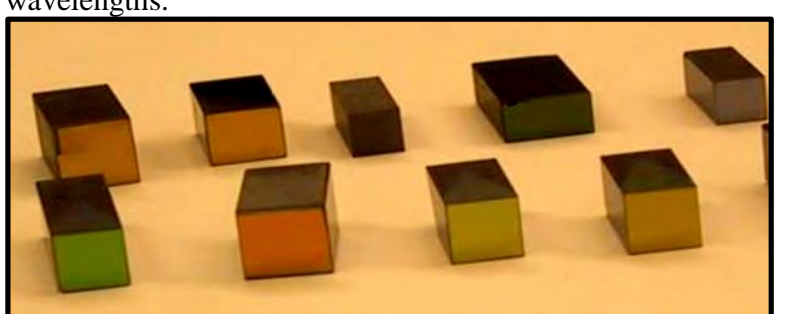

Figure 1. Sampling of ZGP crystals with various outlines and optical coatings

Sliver Gallium Selenite (AgGase2) so indicated as AGS crystals are nonlinear optical (NLO) materials have large effective non-linearity, wide spectral and specially have transmission in the infrared (IR) region, thereforthesetype crystals also demonstrated to efficient frequency doubling medium for infrared radiation(Komine, 1955)(Gary D. Body, 1968).

Useful transmission wave lengths range are from 0.75 to $12 \mu$ mandfrom 0.73 to $18 \mu \mathrm{m}$ from ZnGep2 and AgGase2 respectively, therefore thisstudy is limited in the wave length range from 1 to $12 \mu \mathrm{m}$ (Alnayli, 2008).

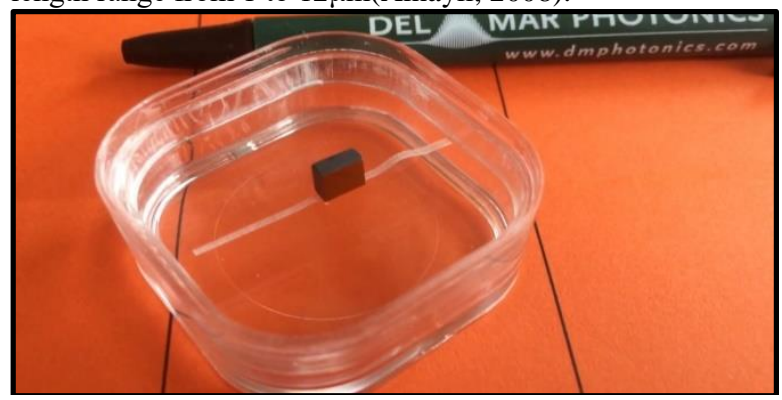

Figure 2. Sliver Gallium Selenide (AgGase $)_{2}$ crystal

Table 1. Optical and Nonlinear Optical Properties for AGS(Nikogosyan, 2003):

\begin{tabular}{|c|c|}
\hline \multicolumn{2}{|c|}{ LINEAR Optical Properties } \\
\hline $\begin{array}{l}\text { Transmitting wave front } \\
\text { distortion }\end{array}$ & $\leq \lambda / 4 @ 633 \mathrm{~nm}$ \\
\hline Bulk damage threshold & $\begin{array}{l}\geq 50 \mathrm{MW} / \mathrm{cm} 2 \text { at } 1064 \mathrm{~nm} \text { for } 10 \\
\mathrm{~ns}, 10 \mathrm{~Hz} \text { pulse }\end{array}$ \\
\hline Flatness & $\geq \lambda / 8 @ 633 \mathrm{~nm}$ \\
\hline Scratch/Dig & $\leq 10 / 5$ \\
\hline \multicolumn{2}{|c|}{ Nonlinear Optical Properties } \\
\hline $\begin{array}{l}\text { Damage threshold of } \\
\text { coating }\end{array}$ & $\begin{array}{l}\geq 50 \mathrm{MW} / \mathrm{cm} 2 \text { at } 1064 \mathrm{~nm} \text { for } \\
10 \mathrm{~ns}, 10 \mathrm{~Hz} \text { pulse }\end{array}$ \\
\hline
\end{tabular}

\section{The Z-Scan Technique}

In 1990 M. Sheik-Bahia(lfalvi, 2003) established a calculated method tocalculate the refraction nonlinearity of thin samples. This is called the $\check{Z}$-scan technique(M. Sheik-Bahae, 1989). The Z-Scan technique has been used to calculate the Nonlinear optical properties of semiconductors, dielectrics, organic or carbon-based molecules and liquid crystals(T. Sivanesan V. N., 2014). This method is rapid, simple to perform and accurate, therefore it is often used. It is especially adequate for determination of a nonlinear coefficient $n_{2}$ for a particular wavelength. The essential geometry is shown in Fig (3).

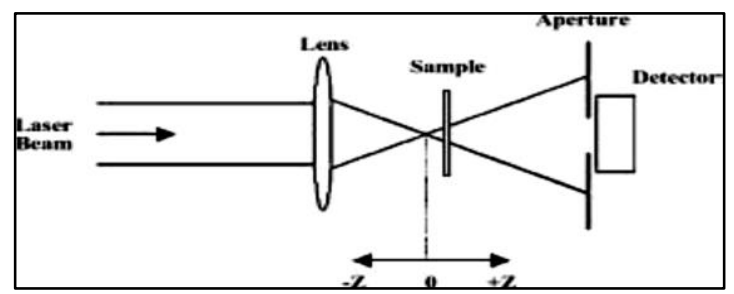

Figure 3. Z-scan experimental arrangement(Mansoor and et al, 2000)

The Z-Scan technique include that the sample is scanned along the $\mathrm{Z}$ direction through the beam waist of a focused Gaussian laser beam in a tight focusing configuration, as seen in Fig.(3). As the sample approaches focus the spot size decreases, increasing the irradiance on the sample and the induced nonlinear effects (Manuel, 2014). There were two parts of the Z-scan: Closed Aperture and Open Aperture.

\subsection{Closed aperture Z- Scan}


Closed aperture Z-scan is an example of self-refractive phenomenon or self-phase modulation in space. Without thenonlinearity absorption, a known peak and valley are showed. If the refractive index nonlinearity $\mathrm{n}_{2}$ of the crystal is negative, the beam gets converged in the prefocal region to get focused closer to the aperture. The beam diameter reducesclose to the aperture, resulting in large amount of through put at the detector(Zahraa S. Shanon, 2016). This results in a peak in the pre focal region. In the post focal region, the same phenomenon results in the divergence of the beam, which results in the decreased transmission through the aperture. Hence, a valley appears in the post-focal region. If the crystal has positive nonlinear refractive, so we get anotheroutcomes (pre focal valley and post focal peak.). The former is called selfdefocusing and the latter is called self-focusing(Zahraa S. Shanon and et al, 2016). The sample has a positive nonlinear refractive index $\left(\mathrm{n}_{2}>0\right)$ when the maximum of the normalization of transmittance follows after the minimum during $\breve{Z}$-scan, on the contrary the sample has self-defocusing properties $\left(\mathrm{n}_{2}<0\right)$, when the transmittance maximum first appears and then minimum(Ule, 2015).

Just like in Fig. (4) that shows the order of scanning the third dimension of positive and negative refraction of Nonlinear.

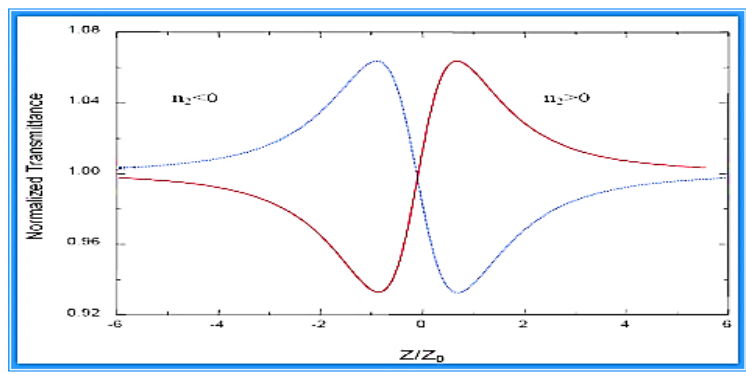

Figure 4. Z-Scan technique -closed aperture bends curves of nonlinear refraction positive and negative(Mansoor and et al, 1990).

The connection between the normalize transmission $\mathrm{T}(\mathrm{z})$ and $\mathrm{z}$ position was acquired by moving the crystals along the axis of the beam direction (z-direction) as for the point to the focal point, We characterize an effortlessly measurable quantity $\Delta \mathrm{T}_{\mathrm{p}-\mathrm{v}}$ as the different between the normalized peak and valley of transmission: $\Delta \mathrm{T}_{\mathrm{p}-\mathrm{v}}$ is linearly-dependent on the transiently averaged induced phase distortion. The variety of this amount as an element of $\Delta \Phi_{\mathrm{o}}$ is given by (T. Sivanesan and et al., 2010):

$\Delta T_{\mathbf{p}-\mathbf{v}}=0.406 \Delta \Phi_{0}$

Where $\Delta T_{P-V}=T_{P}-T_{V}$

$\Delta \mathrm{T}_{\mathbf{p}-\mathbf{v}}$ the difference in transmission between the peak and valley.

The non- linear refractive index can be obtained from the formula:

$n_{2}=\Delta \Phi_{0} / I_{0} L_{e f f} k$

$k=2 \pi / \lambda$

$\lambda$ : wavelength of laser beam.
$I_{0}=2 p / \pi w_{0}^{2}(5)$

$I_{0}$ : is intensity of the laser beam at the focus $(\mathrm{Z}=0)$.

P: power of laser beam

$w_{0}$ : the beam radius at the focal point

$L_{e f f}=\left(1-\exp ^{-\alpha_{0} t}\right) / \alpha_{0}(6)$

$L_{\text {eff }}$ :the effective thickness of the sample, $t$ : is the thickness of the sample, $\alpha_{0}$ :the linear absorption coefficient, which can be found from the curved transmission (Unnikrishnan, 2003)

$\alpha_{0}=\frac{1}{t} \operatorname{Ln} \frac{1}{T}$

Where $t$ : thickness of sample, $\mathrm{T}$ : transmittance

\subsection{Open Aperture Z-Scan:.}

The open aperture $\breve{Z}$-scan method is used to measure the nonlinear coefficient of absorbance $(\beta)$. In this case, the aperture is removed. Therefore, z-scan technique be sensitive to thenonlinear absorption. When the absorption increase in the sample with the increase laser beam intensity, the transmittance minimum in the focal lens as it is shown in figure (5-a), the nonlinear absorption produces from two photon absorption. Whereas it decrease the absorption sample with the increase of laser beam intensity, the transmittance maximum at focal point ,as its illustrated in figure (5-b),the nonlinear produces from Storable absorption(Pau, 2004).

In Factthat, the nonlinear absorption coefficients can be easily calculated from the transmittance curves figure (5) [14].

$\beta=\frac{2 \sqrt{2}}{I_{0} L_{\text {eff }}} \Delta T$

Where $\Delta \mathrm{T}$ is the one peak value at the open aperture $\mathrm{Z}$ scan curve .The value of $\beta$ is positive for storable absorption and negative for two photon absorption(Unnikrishnan, 2003).

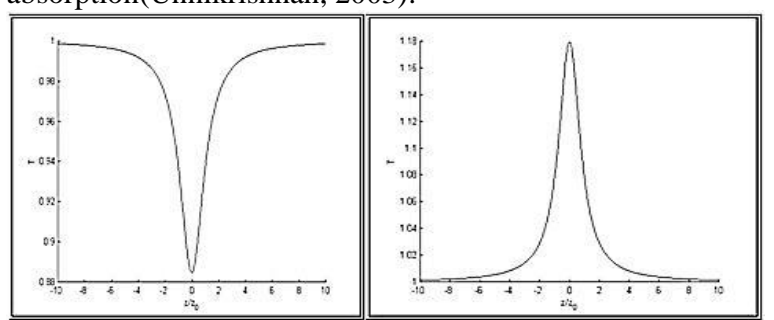

Figure 5. shows Forms Z-Scan technique open aperture(Mansoor and et al., 1989)].

\section{Experimental Part}

Weadditionally studied, the impact of laser intensity on the absorption property, bymeasured the transmission of the crystals at focal position with difference laser intensities. In order to show the nonlinear optical properties at darkness at room temperature and have high stability. The nonlinear optical properties for Zink Germanium Di phosphate $\mathrm{ZnGeP}_{2}$ and Sliver Gallium Selenite $\left(\mathrm{AgGaSe}_{2}\right)$ is explained through $\breve{Z}$-scan results to calculate the nonlinear index of refractive and the nonlinear 


\section{Al-Qadisiyah Journal of Pure Science (QJPS)}

Vol. 23, No.04, pp.14-20, Year-2018

coefficientof absorption. The z- scan experiment illustrates in the figure (6).

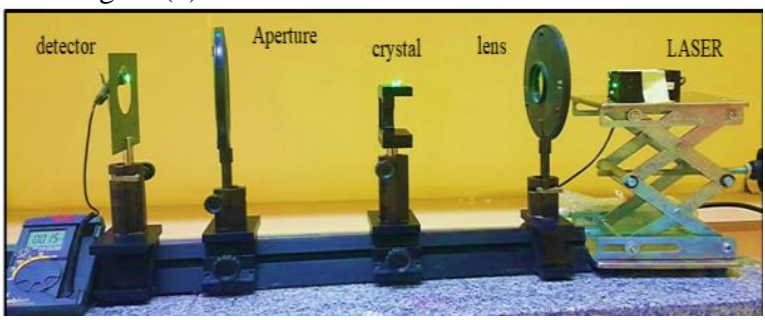

Figure 6. The Setup of Ž- Scan Technique

Figure (6) shows the elements z-scan experiment. In this experiment consisted of the laser frequency doubler $\mathrm{Nd}-$ Yag $532 \mathrm{~nm}$ by a power (25) mw.The second element of z-scan system is collimating lens whose focal length is $15 \mathrm{~cm}$, the lens wasplaced opposite the Nd-yag laser.The crystals with dimensions $\left(6 \times 6 \times 8 \mathrm{~mm}^{3}\right)$ was scanned using transition system along direction $\mathrm{z}$-axis through the focusing area. As well as the aperture place a front detector which its diameter $1 \mathrm{~mm}$, which is used to measure the output power of $\mathrm{CW}$ laser. The detector was placed at the far field of laser beam.

5.Result and Discussion

The nonlinear optical properties wereinvestigated forSliver Gallium Selenite $\left(\mathrm{AgGaSe}_{2}\right)$ and Zink Germanium Di phosphate ZnGeP2crystals and the thickness of the crystals were $(t=8 \mathrm{~mm})$ with power $(25 \mathrm{~mW}, 35 \mathrm{~mW}, 40 \mathrm{~mW}$ and $80 \mathrm{~mW})$. at each $(532$ and $1064 \mathrm{~nm}$ ) of Nd-Yag laser.

5.1 Nonlinear Refractive index

The nonlinear refractive index $\left(\mathrm{n}_{2}\right)$ forSliver Gallium selenite $\left(\mathrm{AgGaSe}_{2}\right)$ andZink Germanium Diphosphate ZnGeP2crystals was measured by the Z-Scan technique .Figure $(7,8,9,10,11$ and 12) shows a Closed-Aperture ZScan technique for Sliver Gallium selenite (AgGase2) and Zink Germanium Di phosphate $\mathrm{ZnGeP}_{2}$ at different laser wavelength $(532 \mathrm{~nm}$ and $1064 \mathrm{~nm})$ with different laser powerful $(25 \mathrm{~mW}, 35 \mathrm{~mW}, 40 \mathrm{~mW}$ and $80 \mathrm{~mW})$.

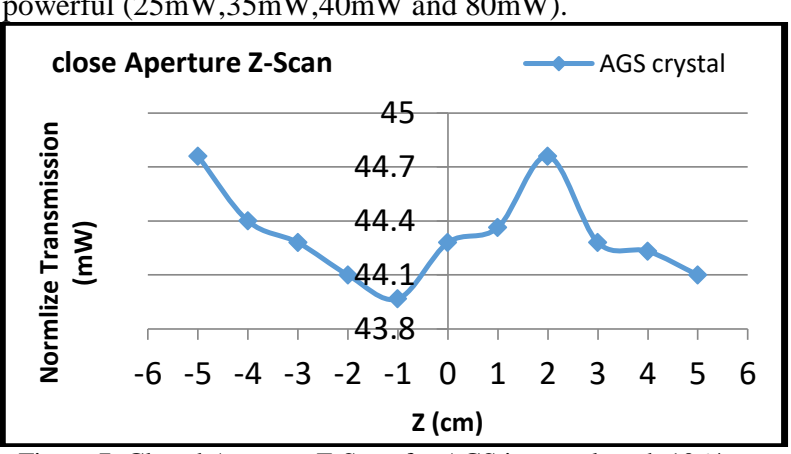

Figure 7. Closed Aperture Z-Scan for AGS in wavelength 1064 $\mathrm{nm}$ at $40 \mathrm{~mW}$

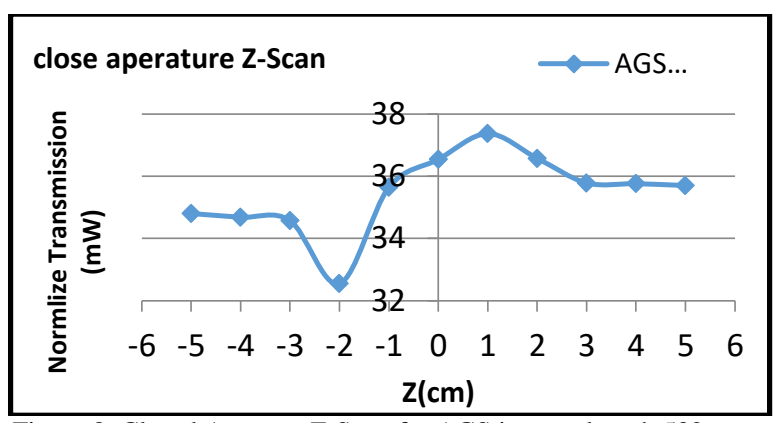

Figure 8. Closed Aperture Z-Scan for AGS in wavelength $532 \mathrm{~nm}$ at $25 \mathrm{~mW}$

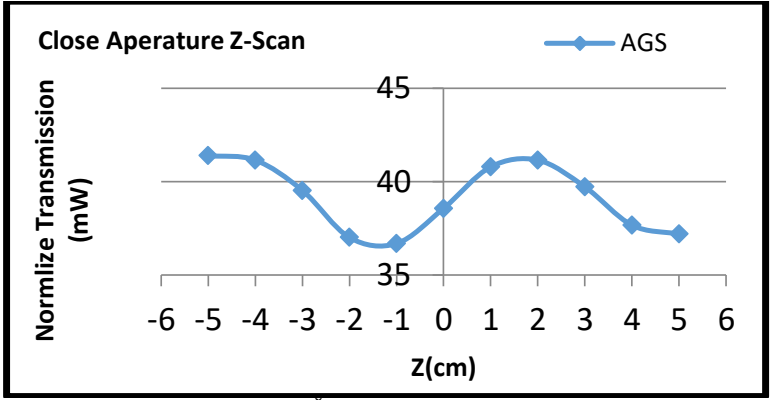

Figure 9. Closed Aperture Ž-Scan for AGS in 532 nmwavelength at $40 \mathrm{~mW}$

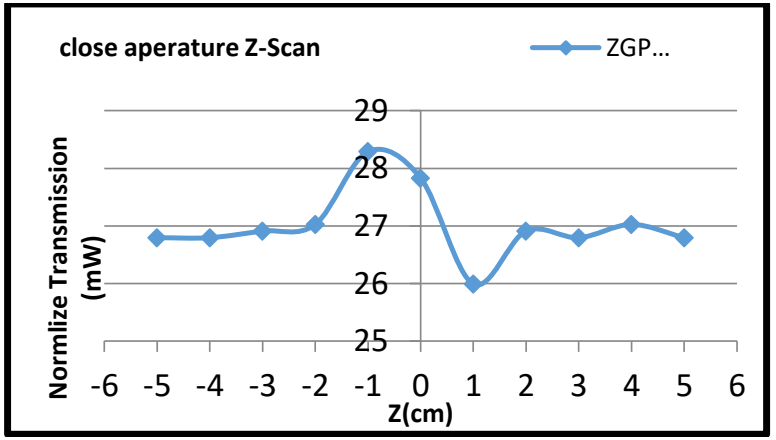

Figure 10. Closed Aperture Z-Scan for ZGP in wavelength $532 \mathrm{~nm}$ at $25 \mathrm{~mW}$

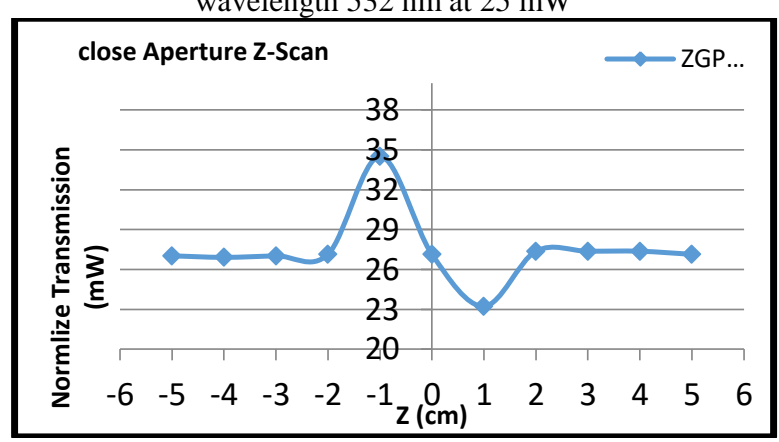

Figure 11. Closed Aperture Z-Scan for ZGP in wavelength $1064 \mathrm{~nm}$ at $35 \mathrm{~mW}$ 
Vol. 23, No.04, pp.14-20, Year-2018

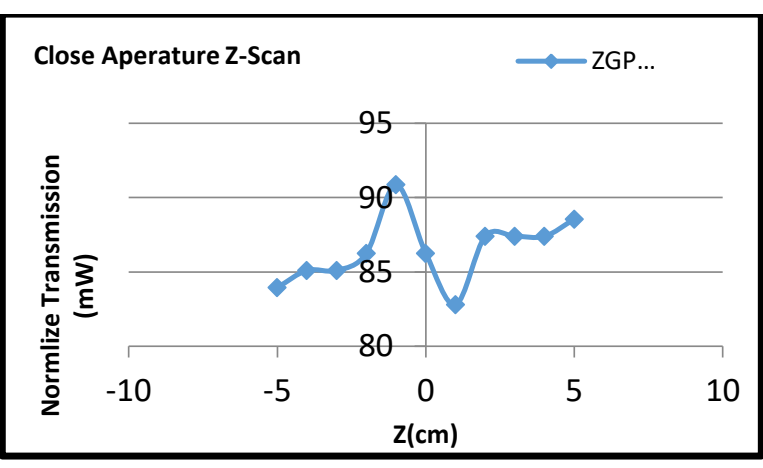

Figure 12. Closed Aperture Z-Scan for ZGP in wavelength $532 \mathrm{~nm}$ at $80 \mathrm{~mW}$

Figures (7,8 and 9) shows thenormalized transmition for the Closed Aperture (CA) curve of AGS. The valley to peak arrangement of this curve [Figure (7,8 and 9) ] shows that the index of refractive is positive, showing a selffocusing effect.

It was observed from the outcomes of Ž-scan methodofAGS crystal that the refractive index of nonlinearity value is $\mathbf{5 . 0 4} \times \mathbf{1 0}{ }^{-10} \mathrm{~cm}^{2} / \mathrm{mW}$ at wavelength $1064 \mathrm{~nm}$, and the value to nonlinear refraction index $\mathrm{n}_{2}$ is $2.4 \times 10^{-9}, 1.5 \times 10^{-9} \mathrm{~cm}^{2} / \mathrm{mW}$ at the wavelength frequency doubler $532 \mathrm{~nm}$ with powers $40,25 \mathrm{~mW}$ receptively. The table (2) is summarized the nonlinear refraction index that calculated for AGS crystal.

Table 2. the experimental result for AGS crystal at Close Aperture

\begin{tabular}{|c|c|c|c|}
\hline \multicolumn{4}{|c|}{ Z-scan } \\
\hline$\lambda(\mathrm{nm})$ & 1064 & 532 & 532 \\
\hline$\Delta(\mathrm{mW})$ & 40 & 25 & 40 \\
\hline$\Delta \mathrm{T}_{\mathrm{P}-\mathrm{V}}$ & 0.79 & 4.824 & 4.704 \\
\hline$\Delta \emptyset_{\mathrm{o}}(\mathrm{Rad})$ & 1.94 & 11.8 & 11.5 \\
\hline $\mathrm{n}_{2}\left(\mathrm{~cm}^{2} / \mathrm{mw}\right)$ & $5.04 \times 10^{-10}$ & $2.4 \times 10^{-9}$ & $1.5 \times 10^{-9}$ \\
\hline
\end{tabular}

While in figures $(10,11$ and 12) show thepeak followed byvalley of transmission achievedfrom the close aperture Z-scan curve of ZGP measurement, indicates that the sign of the refraction index is negative (self-defocusing).

It was observed from the outcomes of Ž-scan method for ZGP crystal that therefraction indexnonlinearity value is $9.1 \times 10^{-9} \mathrm{~cm}^{2} / \mathrm{mW}$ at wavelength $1064 \mathrm{~nm}$, and the value to nonlinear refraction index $\mathrm{n}_{2}$ are $\mathbf{1 . 4} \times \mathbf{1 0}^{-\mathbf{9}}$,

$1.3 \times 10{ }^{-9} \mathrm{~cm}^{2} / \mathrm{mW}$ at the wavelength frequency doubler $532 \mathrm{~nm}$ with powers 25,35 and $80 \mathrm{~mW}$ receptively. The table (3) is summarized the nonlinear refraction index that calculated for ZGP crystal.

Table 3. the experimental result for ZGP crystal at Close Aperture

\begin{tabular}{|c|c|c|c|}
\hline$\lambda(\mathrm{nm})$ & 1064 & 532 & 532 \\
\hline $\mathrm{P}(\mathrm{mW})$ & 35 & 25 & 80 \\
\hline$\Delta \mathrm{T}_{\mathrm{P}-\mathrm{V}}$ & 11.27 & 2.3 & 8.05 \\
\hline$\Delta \emptyset_{\mathrm{o}}(\mathrm{Rad})$ & 27.7 & 5.6 & 19.8 \\
\hline $\mathrm{n}_{2}\left(\mathrm{~cm}^{2} / \mathrm{mw}\right)$ & $9.1 \times 10^{-9}$ & $1.3 \times 10^{-9}$ & $1.4 \times 10^{-9}$ \\
\hline
\end{tabular}

\subsection{Nonlinear Absorption coefficient}

The coefficient of nonlinear Absorption $(\beta)$ for AGS and ZGP was measured by the open aperture Ž- scan experimental result. The coefficient of nonlinear absorption is calculated from the eq. (8).Figures(13,14,15,16,17 and 18) shows Open-Aperture
Z-Scan technique for Sliver Gallium selenite $\left(\mathrm{AgGaSe}_{2}\right)$ andZink Germanium Diphosphate $\mathrm{ZnGeP}_{2}$ crystalsat different laser wavelength $(532 \mathrm{~nm}$ and $1064 \mathrm{~nm})$ with different laser powerful $(25 \mathrm{~mW}, 35 \mathrm{~mW}, 40 \mathrm{~mW}$ and $80 \mathrm{~mW}$ ).

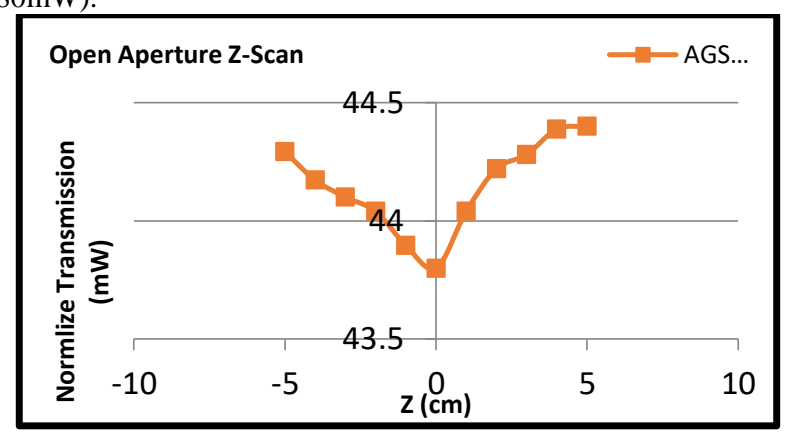

Figure 13. Open aperture Z-Scan for AGS in wavelength $1064 \mathrm{~nm}$ at $40 \mathrm{~mW}$

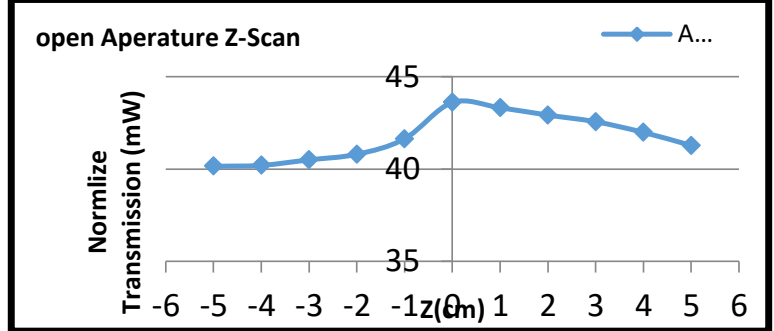

Figure 14. Open aperture Z-Scan for AGS in wavelength $532 \mathrm{~nm}$ at $40 \mathrm{~mW}$

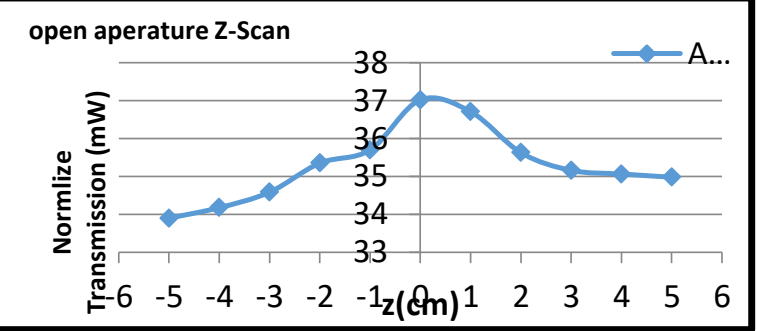

Figure 15. Open aperture Z-Scan for AGS in wavelength $532 \mathrm{~nm}$ at $25 \mathrm{~mW}$

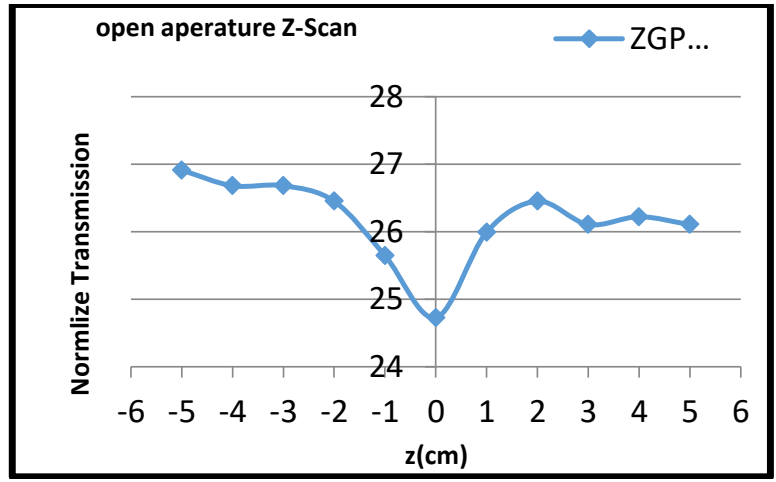

Figure 16. Open aperture Z-Scan for ZGP in wavelength $532 \mathrm{~nm}$ at $25 \mathrm{~mW}$ 
Vol. 23, No.04, pp.14-20, Year-2018

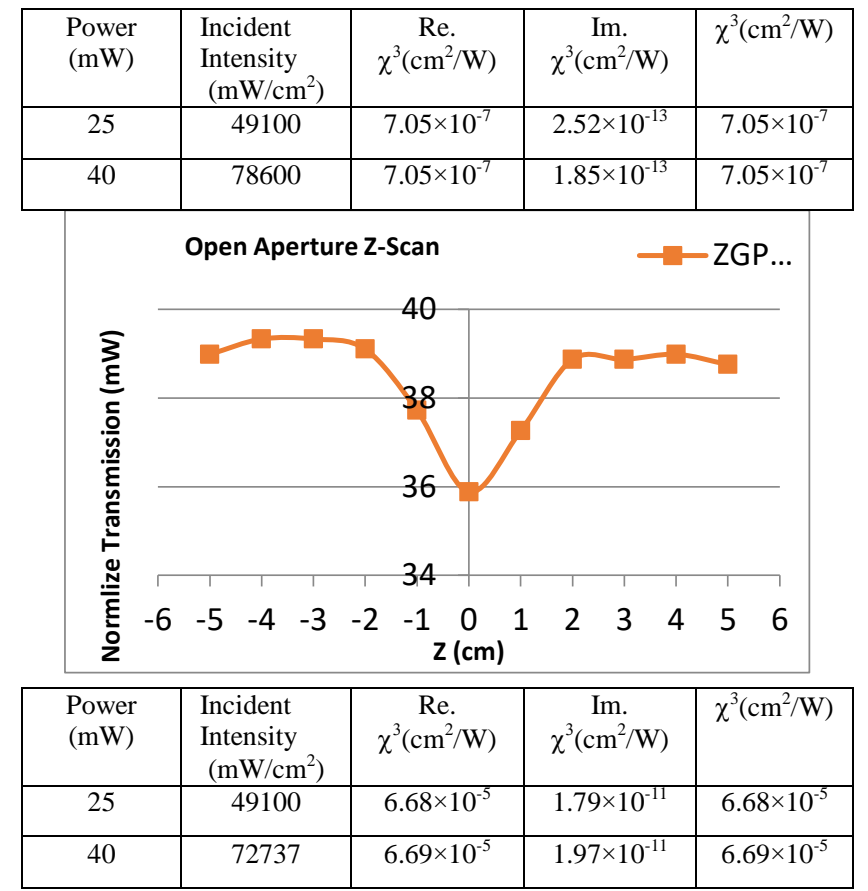

Figure 17. Open aperture Z-Scan for ZGP in wavelength $1064 \mathrm{~nm}$ at $35 \mathrm{Mw}$

Figures $(13,14,15,16,17$ and 18) shows the experimental results for the nonlinear absorption coefficient is because of the effect of saturation and two photon absorption at $1064 \mathrm{~nm}$ Nd-yag CW laser and frequency doubler $532 \mathrm{~nm}$ $\mathrm{CW}$ laser.outcomesof the coefficient of nonlinear absorption for Sliver Gallium selenite $\left(\mathrm{AgGaSe}_{2}\right)$ andZink Germanium Diphosphate ZnGeP2crystals estimated as shown in table (4).

Table (4) the experimental result for AGS and ZGP crystal at Open Aperture z-scan

\begin{tabular}{|c|c|c|c|c|c|c|}
\hline \multicolumn{2}{|c|}{$\lambda=1064(\mathrm{~nm})$} & \multicolumn{5}{|c|}{$\lambda=532(\mathrm{~nm})$} \\
\hline $\begin{array}{c}\text { Power of } \\
\text { laser }\end{array}$ & $\begin{array}{c}40 \\
(\mathrm{~mW})\end{array}$ & \multicolumn{3}{|c|}{ Power of laser $25 \mathrm{~mW}$} & \multicolumn{2}{|c|}{$\begin{array}{c}\text { Power of laser } \\
40 \mathrm{~mW}\end{array}$} \\
\hline $\begin{array}{c}T_{\text {ney }} \\
(\mathrm{mW})\end{array}$ & 43.8 & \multicolumn{2}{|c|}{$\begin{array}{l}T_{\text {ras }} \\
(\mathrm{mW})\end{array}$} & 37.02 & $\begin{array}{l}\mathrm{T}_{\mathrm{Rn \mu w}} \\
(\mathrm{mW})\end{array}$ & 43.6 \\
\hline $\begin{array}{c}\beta \\
(\mathrm{cm} / \mathrm{mm})\end{array}$ & $\begin{array}{r}1.89 \\
\times 10^{-3}\end{array}$ & \multicolumn{2}{|c|}{$\underset{(\mathrm{cm} / \mathrm{mw})}{\beta}$} & $\begin{array}{r}2.57 \\
\times 10^{-3}\end{array}$ & $\underset{(\mathrm{cm} m}{\beta}$ & $\begin{array}{r}1.89 \\
\times 10^{-3}\end{array}$ \\
\hline \multicolumn{7}{|c|}{$\begin{array}{ll}\text { Open aperture Z-Scan results for ZGP } \\
\end{array}$} \\
\hline \multicolumn{2}{|c|}{$\lambda=1064(\mathrm{~nm})$} & & \multicolumn{4}{|c|}{$\lambda=532(\mathrm{~nm})$} \\
\hline $\begin{array}{l}\text { Power of } \\
\text { laser }\end{array}$ & \multicolumn{2}{|c|}{$\begin{array}{c}35 \\
\text { (mW) }\end{array}$} & \multicolumn{4}{|c|}{ Power of laser $25 \mathrm{~mW}$} \\
\hline $\begin{array}{c}T_{\text {new }} \\
(\mathrm{mW})\end{array}$ & \multicolumn{2}{|c|}{35.8} & \multicolumn{2}{|c|}{$\begin{array}{l}T_{\text {new }} \\
\text { (mW) }\end{array}$} & \multicolumn{2}{|l|}{24.7} \\
\hline$\beta(\mathrm{cm} m w)$ & \multicolumn{2}{|c|}{$1.9 \times 10^{-4}$} & \multicolumn{2}{|c|}{$\beta(\mathrm{cm} / \mathrm{mw})$} & \multicolumn{2}{|c|}{$1.9 \times 10^{-3}$} \\
\hline
\end{tabular}

\subsection{NonlinearSusceptibility estimations}

The real $\left(\operatorname{Re} \chi^{(3)}\right)$ and imaginary $\left(\operatorname{Im} \chi^{(3)}\right)$ parts of the third order nonlinear optical susceptibility $\chi^{(3)}$ were determined from experimental results of nonlinear refractive index $n_{2}$ and the nonlinear absorption coefficients $\beta$ according to the following relations[21]:

$\operatorname{Re} \chi^{(3)}(e s u)=10^{-4} \frac{\varepsilon_{0} C^{2} n_{o}^{2}}{\pi}\left(\frac{\mathrm{cm}^{2}}{\mathrm{~W}}\right)$
$\operatorname{Im} \chi^{(3)}(e s u)=10^{-2} \frac{\varepsilon_{0} C^{2} n_{o}^{2} n_{2} \lambda \beta}{4 \pi^{2}}\left(\frac{\mathrm{cm}^{2}}{\mathrm{~W}}\right)$

Where, $\mathrm{c}$ : is the speed of light, $\lambda$ : is the wavelength.

The absolute value $\left|\chi^{(3)}\right|$ of was calculated from the following relation :

$\left|\chi^{(3)}\right|=\left[\left(\operatorname{Re}\left(\chi^{(3)}\right)\right)^{2}+\left(\operatorname{Im}\left(\chi^{(3)}\right)^{2}\right]^{\frac{1}{2}}\right.$

As shown the results in table (5) and (6).

Table 5.The result of the real and imaginary parts of the third order nonlinear optical susceptibility $\chi^{(3)}$ for AGS crystal

Table 6 . The result of the real and imaginary parts of the third order nonlinear optical susceptibility $\chi^{(3)}$ for ZGP crystal

\section{Conclusion}

It was investigated nonlinear optical of Sliver Gallium selenite $\left(\mathrm{AgGase}_{2}\right)$ andZink Germanium Diphosphate $\mathrm{ZnGeP}_{2}$ crystalsat diminution $6 \times 6 \times 8 \mathrm{~mm}^{3}$.The $\mathrm{z}$-scan technique was used with continuous wave $(\mathrm{CW}) \mathrm{Nd}-\mathrm{yag}$ laser at two wavelengths $1064 \mathrm{~nm}$ and $532 \mathrm{~nm}$ for measuring the nonlinear optical properties of Sliver Gallium selenite $\left(\mathrm{AgGase}_{2}\right)$ and Zink Germanium Diphosphate $\mathrm{ZnGeP}_{2}$ crystals, suchas the index of nonlinear refractive $\left(n_{2}\right)$,thecoefficient ofabsorbance $(\beta)$. It is found that the AGS crystal shows nonlinear saturation absorption and a positive nonlinear refractive index $\left(\mathrm{n}_{2}\right)$, leads to self-focusing refraction effect. While the ZGP crystal shows nonlinear two-photon absorption and a 


\section{(QJPS)}

Vol. 23, No.04, pp.14-20, Year-2018

negative nonlinear refractive index $\left(\mathrm{n}_{2}\right)$, leads to selfdefocusing refraction effect.

\section{REFERENCES}

Alnayli, R. S. (2008). Study on laser frequency conversion with AGS and ZGP crystals. journal of AlQadisiya for pure Sciences, pp. 101-109.

Body, R. W. (2007). Nonlinear optics. New York: rochester.

Hiromi K. (1955), I. J. (1955). Selected Topics in Quantum Electronics . IEEJ, pp. 1,44.

Krishnan R. Parameswaran, R. K. (2002). Highly efficient second-harmonic generation in buried waveguides formed by annealed and reverse proton exchange in periodically poled lithium niobate. Optics Letters, pp. 43-45.

'1falvi, L.' . (2003). Z-scan study of the nonlinear optical properties of LiNbO3. University of PE'CS.

Mansoor Sh. Bahae, Ali. A. H. (1990, April 4), "ASensitive Measurement Of Optical Nonlinearities Using A Single Beam". IEEE Journal Of Quantum Electronics, p. 760.

Mansoor Sh. Bahae, Michael P. Hasselbeck, 2000, Third Order Optical Nonlinearities, Vol. Iv, Chapter. 17, OSA Handbook Of Optics, New Mexico, Albuquerque, P. 27.

Mansoor. Sh. Bahae, A. A. (1989, September 1). Highsensitivity, single-beam n2 measurements. Journal of Optics Letters , p. 955.

Manuel R. Ferdinandus, 2014, Techniques For Characterization Of Third Order Optical Nonlinearities, Thesis , University Of Central Florida, Orlando, Florida

Marder, Sh. (1991, march 11). Materials for Nonlinear Optics. Chemical Perspectives, ACS Symposium Series 455,American Chemical Society, Washington DC.

Nikogosyan, N. (2003). Nonlinear Optical Crystals: A Complete Survey . Cork, Ireland: University College Cork.

Peter .A. Franken A. E. Hill, C. P. (1961, Augest 15). GENERATION OF OPTICAL HARMONICS. Physical Review Letters, p. 118.

Gary D. Body and Arthur K. Parametric Interaction of Focused Gaussian Light Beams. (1968, july). Journal of Applied Physics, p. 3597.

Sutherland, R. L. (2003). Hand Book Nonlinear Optics. U.S.A.: Dayton.

Sivanesan T., Natarajan V., (2010). Non-linear optical properties of $\alpha$-glycine single crystals by Z-Scan technique. Indian Journal of Science and Technology, p. 653.

Sivanesan T., Natarajan V., Jayaraman D. and Pandi S., (2014). Third order Non- Linear optical properties of Vanillin Single Crystals by Z-Scan Technique . Scholars Research Library, pp. 1621.

Ule, E. (2015). Measurement of The Nonlinear Refractive Index by Z-scan Technique. Slovenia : University of Ljubljana.

Unnikrishnan, (2003). Z-scan and Degenerate Four Wave Mixing Studies in Certain Photonic Materials.
India: Cochin University of Science \& Technology.

Zahraa S. Shanon, Raad Sh. (2016, Augest). Study of the Nonlinear Optical Properties of Lithium Triborate Crystal by Using Z-Scan. International Journal of Science and Research (IJSR), p. 1683.

Zahraa S. Shanon, Raad Sh. (2016, Augest). Study of the Second and Third Harmonics Generation in Lithium Triborate Single Crystal. International Journal of science and Research (IJSR), pp. 1614-161 
